\title{
A Technological Platform and a Process to Implement the Informative Marketing Strategy ${ }^{\dagger}$
}

\author{
Daniele Di Valerio ${ }^{1}$, Martina Marinelli ${ }^{1}$, Gaetanino Paolone ${ }^{1}$, Francesco Pilotti ${ }^{1}$, Samanta Vellante ${ }^{1}$ \\ and Paolino Di Felice ${ }^{2, *(1)}$ \\ 1 Software Industriale, 64100 Teramo, Italy; d.divalerio@softwareindustriale.it, m.marinelli@softwareindustriale.it, \\ g.paolone@softwareindustriale.it,f.pilotti@softwareindustriale.it, s.vellante@gruppocomit.it \\ 2 Department of Industrial and Information Engineering and Economics, University of L'Aquila, \\ 67100 L'Aquila, Italy; paolino.difelice@univaq.it \\ * Correspondence: paolino.difelice@univaq.it; Tel.: +39-320-423-2540 \\ + Presented at 1st International Electronic Conference on Applied Sciences, 10-30 November 2020; Available online: \\ https://asec2020.sciforum.net/.
}

Published: 10 November 2020

\begin{abstract}
Context: There is large evidence in the literature that digitalisation improves the market performance of enterprises and, as a consequence, it helps the growth of their businesses. Through digital platforms companies connect with people, improve awareness of their brands, influence consumer's attitudes, collect feedback from them, improve products and services on sale and, at last, increase their incomes. (2) Method: We carried out a context analysis on the current status of research related to digital platforms in order to identify their distinguishing "dimensions" and then, come up with a sound definition for the IT-platform concept. (3) Results: In light of the study of the literature, it was possible: (a) to set the IT components necessary to build a digital platform suitable to support companies in implementing the Informative Marketing strategy; (b) to detail a process that implements such a marketing strategy by means of a adopted actual digital platform.
\end{abstract}

Keywords: Informative Marketing; Technological Platform, Process

\section{Introduction}

Billions of people around the world spend every day an increasing amount of time online searching for information about products and services. Two conditions must be satisfied so that a consumer chooses a specific brand among many: (a) the brand must be in his choice set; (b) the brand must be preferred over the other brands in the choice set. The main finding of Clark et al. [1], got by using data on three hundred brands across 19 categories, was that advertising expenditures have a significant positive effect on brand awareness but no significant effect on perceived quality. Based on this, Clark et al. conclude that providing basic information should be the dominant role of advertising. This typology of advertising is called Informational in [2] and described as follows. The informational message strategy presents factual product/services information in clear and concrete terms. Informational messages enable consumers to objectively assess the benefits, functional attributes, and applications of products and services. This message strategy is rationally oriented, informing consumers about how products/services can solve their problems or fulfil their needs. In summary, from [2] it follows that for an advertisement to be judged informational it must reflect the following characteristics: (a) present factual, relevant information about the brand; (b) contains information which is important to the potential consumer; (c) mentions verifiable 
data. Obviously, in order for an informational advertisement to become informative the message must be perceived as such by consumers. The notion of Informational Marketing discussed in [3] is built on top of the notion of Informational Advertising in [2].

There is large evidence in the literature that digitalisation improves the market performance of enterprises and, as a consequence, it helps the growth of their businesses. The interface between producers and consumers is the digital platform. The final goal of our industrial project is to make available to the potential stakeholders a generator of digital platforms that implements the emerging low-code paradigm. In other words, by making recourse to such a generator, potential stakeholders will be able to instantiate by themselves the digital platform that best responds to the needs of their businesses. The work by Sanchis et al. [4], for example, emphasises the role of the low-code paradigm as an enabler of digital transformation in the Manufacturing Industry.

This study builds upon two research questions:

RQ1. What is the current status of research related to digital platforms?

RQ2. What are the IT components necessary to build a digital platform suitable to support companies in implementing an Informative Marketing (IM) strategy?

The present paper provides an answer to both questions above, moreover it details the process that implements the IM strategy by means of a specific architecture of the digital platform. We use the adjective informative instead of informational because the advertisings about the product/service are sent to a community of ad hoc recruited stakeholders, therefore we can assume as relevant the information they receive. Overall, the present short paper is an implementation-oriented contribution in the Information System area of modern enterprises.

\section{Methods}

Digital platforms are a pervasive technology that is transforming the ways in which products and services are produced and consumed. As a consequence a large body of research has been devoted to this topic. Tiwana (2014) [5], Sun et al. (2015) [6], Parker et al. (2016) [7], de Reuver et al. (2017) [8], Asadullah et al. (2018) [9], Hein et al. (2019) [10], and Hein et al. (2020) [11] is an incomplete list of recent papers the reader may refer to. Scholars from various disciplines have adopted different perspectives about digital platforms. The consequence is the lack of a common understanding (both in research and industry) about the meaning of the term platform, even when it is related to a specific domain. This is the case, for instance, of the IT domain, as pointed out by Sun et al. [6].

As the first step of our research, we carried out a context analysis on the current status of research related to digital platforms in order to identify their distinguishing "dimensions" and then, come up with a sound definition for the IT-platform concept. The conclusion of this investigation can be summarised as follows. In this paper we adopt the IT-platform conceptual model given by Sun et al. (2015) [6] (see Fig. 1), as a result of the review of 132 relevant articles, and the linked definition they propose: "An IT-platform is defined as comprised of a technological base on which complementary add-ons can interoperate, following standards and allowing for transactions amongst stakeholders, within the platform-centric ecosystem." The six concepts (called dimensions in [6]), part of the previous definition, are briefly recalled below.

The technological base is the foundation that allows the development of add-ons. A standard is a set of rules enabling developers to interact with the technological base. An add - on is a software module that connects to the technological base to add functionality. Interoperability allows the interaction between a technological base and the add-ons. Transactions denote the interactions within an IT-platform "ecosystem". Governance concerns policies, structures, processes, and mechanisms involved in managing an IT-platform. 


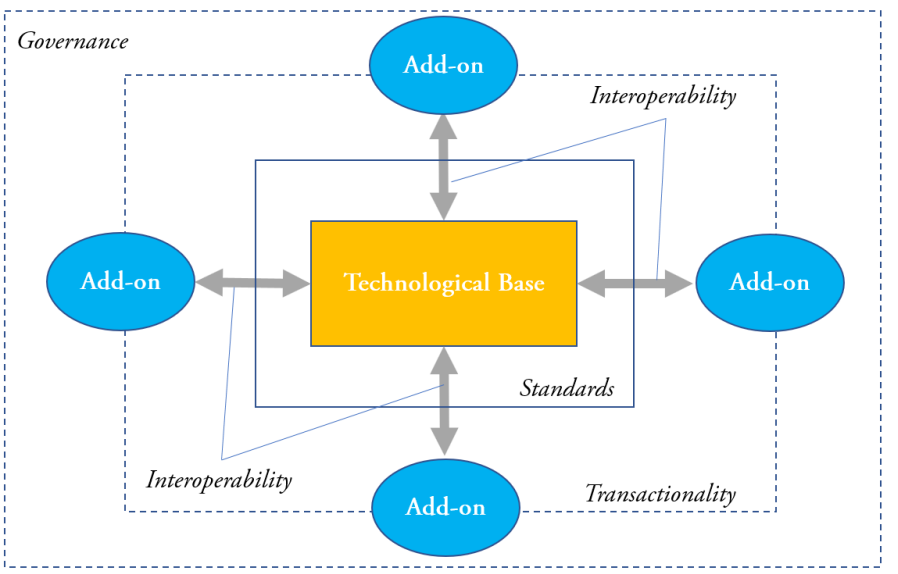

Figure 1. An IT-platform conceptual model [6].

"Ecosystem" is a further concept developed around digital platforms [5]. A digital platform ecosystem consists of two major elements: the platform and the complementary add-ons. The ecosystem comprises platform owners, developers, and consumers.

\section{Results and Discussion}

The platform conceptual model proposed by Sun et al. [6] is an abstract digital platform since its definition is independent of the actual IT technologies that might be used to instantiate their model. Next section introduces an actual digital platform that instantiates the abstract one.

\subsection{The Technological Platform}

Fig.2 shows our instantiation of the platform conceptual model of Fig.1, while Fig.3 shows the components of the InfoMk Technological Base. (InfoMk stands for Informative Marketing.) The basic constraint for the realization of the InfoMk Technological platform is that the Technological Base refers to either a single product/service or to a single category of products/services. The InfoMk Technological Base is a website developed with Microsoft.net technology, on top of a Microsoft SQLServer database.

The website technology is the "heart" of the digital platform of Fig.2. Websites are still largely used across companies all over the world. Below, we mention two studies of 2020 that confirm such a claim. As the first example, it is worth mentioning the study by Sharma et al. [12]. They have explored the digital marketing tools used by small travel agencies in Dheli (India). Most of the respondents said that a website is a must. Travel companies use websites for creating their presence in the online market. "Findings revealed that website is not only for communicating with consumers but is also a tool for authentication. The website assures that the travel suppliers are genuine and is not fly by night kind of company." The study by Said et al. [13] assessed the direct-to-consumer digital marketing technologies (in terms of prevalence and effectiveness) more often adopted in Saudi Arabia by pharmaceutical companies for their promotions. Healthcare websites, social media networks, emails, and webinars/webcasts were analysed in the study. According to Said et al., pharmaceutical companies are becoming the main drivers in the Country of introducing digital technologies in the healthcare sector in the search for more effective communication with consumers. The research findings showed that, according to the respondents (i.e., pharmacists and consumers), pharmaceutical promotional tools were more prevalent on healthcare websites. The authors state that these results are in line with previous studies in the same domain. 


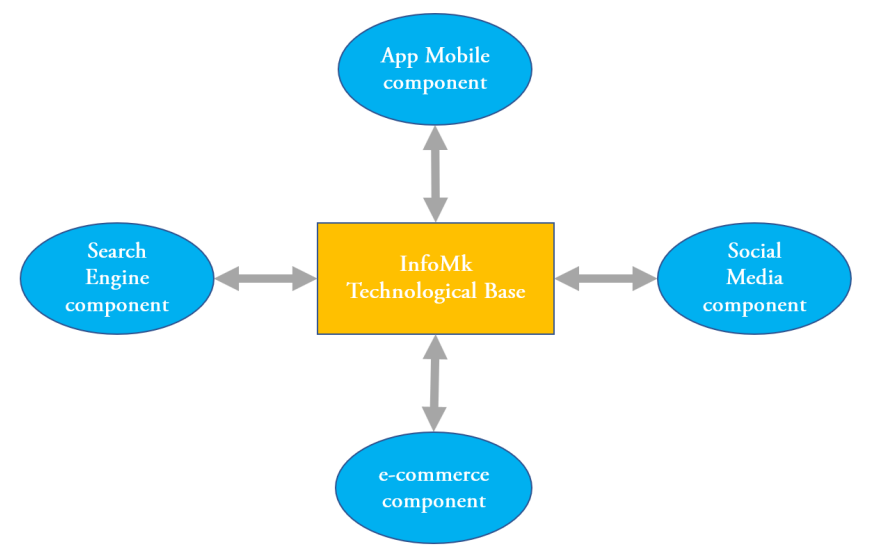

Figure 2. The InfoMk technological platform.

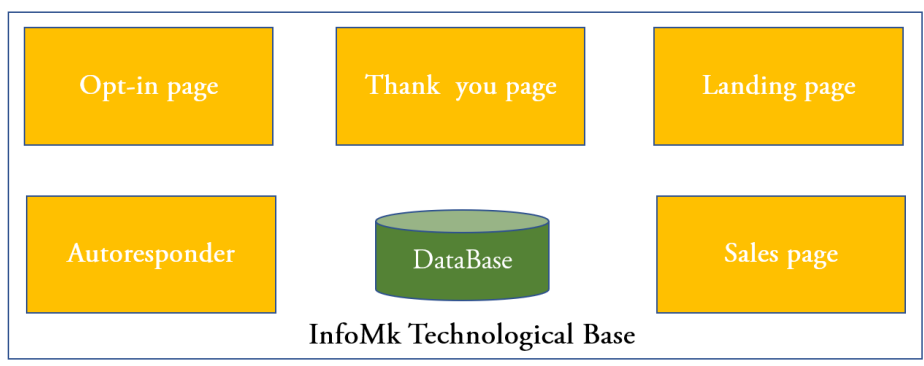

Figure 3. The components of the InfoMk technological base.

Below, we briefly describe the components in Fig.3. Landing pages are single webpages that are focused on one goal (typically the presentation of a product/service). The goal is pursued through any number of different actions (e.g., sign up for a free trial, register for a webinar, etc). The landing page may contains text, an audio file, and/or a video. Opt-in pages (formerly referred to as "subscribe" pages) are webpages where the visitor can subscribe to receive communications (e.g., newsletters or promotional emails). Opt-in pages are a concise landing page focused on getting the email address (and hopefully the name and/or the phone number) of the visitor. Building an email list is one of the most important things companies can do to transform web traffic into marketable contacts. Opt-in pages contains a short text, an image and a "call to action" button. A typical Thank you page consists of saying thank you for subscribing to your service or buying your software or whatever the Opt-in page is about. But, other than the obvious message, an effective Thank you page also tells customers what they should expect next, it should present them with another action they can take that can add value to something they already have and it should guide the customers as to what they should do next. Autoresponder is a software module designed to deliver tailored emails to a list of contacts on a scheduled basis. The Sales page contains the detailed description of the product/service, the selling price and, optionally, a promotional policy. The Sales page is linked to the e-commerce portal. This latter is external to the InfoMk technological platform (Fig.2). All data supporting the previous described components are stored into an SQLServer database.

The Add-ons of the InfoMk Technological Platform are the four components of Fig.2: (a) Apps Mobile (Android and iOs); (b) Social Media Subsystems (for the management and publication of the messages); (c) Search Engine Subsystems (for the management and publication of the ads), and an e-commerce subsystem. 
The Search Engine Subsystem includes a Search Engine Optimization module. The role of such a module on keeping the user on the site is well-known (see, for instance, [14]).

\subsection{The IM Process}

This section describes the steps of the IM process based on the adoption of the Technological Platform of Sec.3.1. Preliminarily it is necessary to accomplish the following activities:

A1 installation of the InfoMk-Technological-Base;

$A 2$ choice of the product/service to be promoted/selled;

A3 creation of the information content (i.e., audio/video-reports) that describes the chosen product/service. The messages must have the three characteristics mentioned in Sec.1, namely: (i) present factual, relevant information about the brand; (ii) contains information which is important to the prospective consumer; (iii) shows verifiable data;

A4 writing of a certain number of emails to be addressed to the prospective stakeholders;

$A 5$ set up a date schedule for the emails;

A6 creation of the Opt-in page, Thank you page, Landing page and Sales page about the chosen product/service.

The IM process is the following. The first step is devoted to attract and recruit stakeholders in order to build a brand community [15] (to be stored into the SQLServer database). The discussion of the methods and principles that guide the construction of communities is out of scope. The adopted community structure is of type Guru [16]. This step begins by sending a message and/or an advertising and/or a SEO campaign through digital channels. The goal is to attract prospective consumers to the Opt-in page, the entry point of the InfoMk Technological base. Downstream of the Opt-in page, the flow of the IM process proceeds as described by the arrows in Fig.4. That is, the stakeholder receives an email of thanks, then he is brought to the Landing page where he finds further information about the product/service in addition to the link for downloading the first informative audio/video report. At this point, the Autoresponder must be activated, which will be responsible for sending the email sequence to the stakeholders according to the chosen timing (A5). Some of the emails in the sequence may contain the link for downloading further informative audio/video reports.

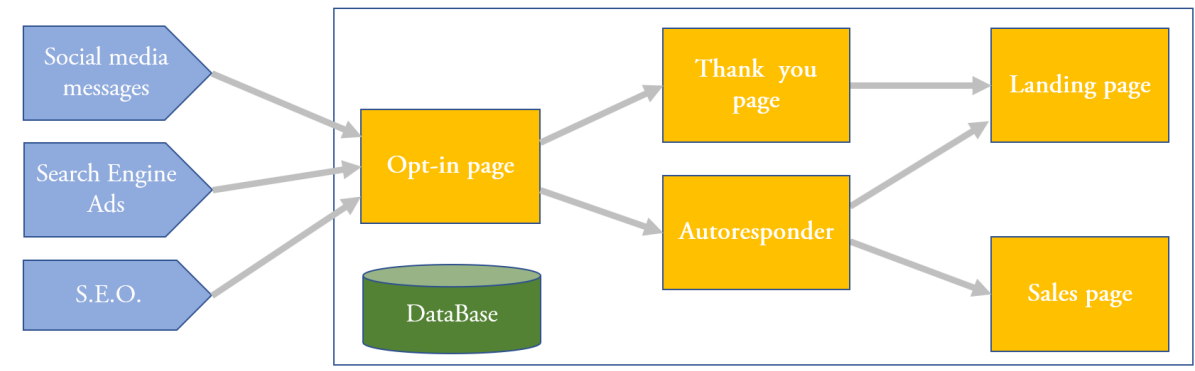

Figure 4. The IM process.

\section{Conclusions and Future Work}

This short paper reported about the preliminary steps of an industrial project aiming at releasing a generator of digital platforms that implements the emerging low-code paradigm. Initially, we investigated the state of the art about digital platforms. At the end of this phase, we decided to adopt the IT-platform conceptual model given by Sun et al. [6] because it offers a sound and general base to start from. This 
study made two contributions. First, we instantiated the abstract platform by means of well-known digital technologies; then we detailed the process that implements the Informative Marketing strategy on top of the proposed digital platform.

The architecture of the actual digital platform and the adopted digital technologies make it suitable both for companies whose primary goal is selling and hence making profit, as well as, for example, for national institutes of health to promote campaigns on healthy (and sustainable) food consumption. In connection with the latter point, Formoso et al. (2020) [17] pointed out that the aspects of the "food system" to be taken into account to promote a correct food consumption besides production, processing, distribution, labelling, promotion, concern the marketing strategies. Implementing the IM strategy is a fundamental tile in this complex puzzle since it can steer consumers towards an informed choice of healthy (and sustainable) food consumption.

As future work, first of all we plan to enrich the functionality of the proposed technological platform so that it can interact with all the available digital tools (among the others, smart watches). Our second goal is to provide support to producers in building and interacting with different types of communities. As mentioned in the Introduction, the final aim of the industrial project is to deliver a generator of the proposed actual digital platform.

Author Contributions: "conceptualization, Paolone and Di Valerio; methodology, Paolone; software, Marinelli; investigation, Di Valerio and Pilotti; data curation, Marinelli and Pilotti; writing-original draft preparation, Paolone and Vellante; supervision, Di Felice; funding acquisition, Paolone"

Funding: "This research was funded by Gruppo SI."

Conflicts of Interest: "The authors declare no conflict of interest.".

\section{References}

1. Clark, C.K., Doraszelski, U., and Draganska, M.: The effect of advertising on brand awareness and perceived quality: An empirical investigation using panel data. Quantitative Marketing and Economics 2009 7, $207-236$ DOI 10.1007/s11129-009-9066-z

2. Puto, C.P. and Wells, W.D.: "Informational and Transformational Advertising: the Differential Effects of Time", in Advances in Consumer Research Volume 11, eds. Thomas C. Kinnear, Provo, UT, 1984 638-643.

3. Tafesse, W. and Wien, A.: Using message strategy to drive consumer behavioral engagement on social media. The Journal of Consumer Marketing 2018, 35(3), 241-253.

4. Sanchis, R., García-Perales, Ó., Fraile, F. and Poler, R.: Low-Code as Enabler of Digital Transformation in Manufacturing Industry. Applied Sciences 2019, 10, 12; doi:10.3390/app10010012

5. Tiwana, A.: Platform ecosystems: Aligning architecture, governance, and strategy. Burlington, Morgan Kaufmann, 2014.

6. Sun, R., Gregor, S., and Keating, B.: Information Technology Platforms: Conceptualisation and a Review of Emerging Research in IS Research, Australasian Conference on Information Systems, Dec. 2015, Adelaide, Australia.

7. Parker, G.G., Van Alstyne, M.W., and Choudary, S.P. Platform revolution. W.W. Norton\& company 2016.

8. de Reuver,M., Sørensen, C.,\& Basole, R. The digital platform: A research agenda. Journal of Information Technology, 2017 33(2), 124-135.

9. Asadullah, A., Faik, I., and Kankanhalli, A. Digital Platforms: A Review and Future Directions. Twenty-Second Pacific Asia Conference on Information Systems, Japan, Sept. 2018.

10. Hein, A., Schreieck, M., Wiesche, M., Böhm,M., and Krcmar, H. The Emergence of Native Multi-Sided Platforms and Their Influence on Incumbents. Electronic Markets 2019. https:/ / doi.org/10.1007/s12525-019-00350-1

11. Hein, A., Schreieck, M., and Riasanow, T. David Soto Setzke, Manuel Wiesche, Markus Böhm, and Helmut Krcmar: Digital platform ecosystems. Electronic Markets 2020 30:87-98 https:/ /doi.org/10.1007/s12525-019-00377-4 
12. Sharma, A., Sharma, S., and Chaudhary, M.: Are small travel agencies ready for digital marketing? Views of travel agency managers Tourism Management 202079104078

13. Said, Y.B., Bragazzi, N.L. and Pyatigorskaya, N.V.: Prevalence and Perceived Effectiveness of Pharmaceutical Digital Marketing among Community Pharmacies in Saudi Arabia: A Cross-Sectional Questionnaire-Based Survey Pharmacy 2020, 8, 9; doi:10.3390/pharmacy8010009

14. Egria, G. and Bayrakb, C.: The Role of Search Engine Optimization on Keeping the User on the Site. Procedia Computer Science 362014335 - 342 doi: 10.1016/j.procs.2014.09.102

15. Brogia, S.: Online brand communities: a literature review. 2nd World Conference on Business, Economics and Management 2003 Procedia - Social and Behavioral Sciences 1092014 385-389.

16. Mudambi, S.M., Oliva, T.A., and Thomas, E.F.: Industrial marketing firms and knowledge transfer: Toward a basic typology of community structures. Industrial Marketing Management 38 2009 181-190 doi:10.1016/j.indmarman.2008.12.006

17. Formoso, G. et al.: An Italian Innovative Small-Scale Approach to Promote the Conscious Consumption of Healthy Food. Applied Sciences 2020, 10, 5678; doi:10.3390/app10165678

(c) 2019 by the authors. Licensee MDPI, Basel, Switzerland. This article is an open access article distributed under the terms and conditions of the Creative Commons Attribution (CC BY) license (http:/ / creativecommons.org/licenses/by/4.0/). 